10 Centorrino F, Price BH, Tuttle M, Bahk WM, Hennen J, Albert MJ, et al. EEG abnormalities during treatment with typical and atypical antipsychotics. Am J Psychiatry 2002; 159: 109-15.

11 Falkenberg I, Benetti S, Raffin M, Wuyts P, Pettersson-Yeo W, Dazzan P, et al. Clinical utility of magnetic resonance imaging in first-episode psychosis. Br J Psychiatry 2017; 211: 231-7.

12 Espay AJ, Aybek S, Carson A, Edwards MJ, Goldstein LH, Hallett M, et al. Current concepts in diagnosis and treatment of functional neurological disorders. JAMA Neurol 2018; 75: 1132-41.

13 Howard LM, Wessely S. Reappraising reassurance: the role of investigations. J Psychosom Res 1996; 41: 307-11.

14 Chang CK, Harrison S, Lee W, Taylor D, Stewart R. Ascertaining instances of neuroleptic malignant syndrome in a secondary mental healthcare electronic medical records database: the SLAM BRC case register. Ther Adv Psychopharmacol 2012; 2: 75-83.

15 Al-Shahi Salman R, Whiteley WN, Warlow C. Screening using wholebody magnetic resonance imaging scanning: who wants an incidentaloma? J Med Screen 2007; 14: 2-4.

16 Keuss SE, Parker TD, Lane CA, Hoskote C, Shah S, Cash DM, et al. Incidental findings on brain imaging and blood tests: results from the first phase of Insight 46, a prospective observational substudy of the 1946 British birth cohort. BMJ Open 2019; 9(7): e029502.

17 Mughal Z, Narayanan A, Gupta V, Reay-Jones N. Clinical need-directed blood tests: a step in saving the NHS? Ann Clin Biochem 2016; 53: 568-74.

18 Arce-Cordon R, Perez-Rodriguez MM, Baca-Baldomero E, Oquendo MA, Baca-Garcia E. Routine laboratory screening among newly admitted psychiatric patients: is it worthwhile? Psychiatr Serv 2007; 58: $1602-5$

19 Faulkner A, Reidy M, McGowan J. Should we abandon routine blood tests? BMJ 2017; 357: j2091.

20 Adams GS, Converse BA, Hales AH, Klotz LE. People systematically overlook subtractive changes. Nature 2021; 592: 258-61.

21 Foy AJ, Filippone EJ. The case for intervention bias in the practice of medicine. Yale J Biol Med 2013; 86: 271-80.

22 Anderson RE. Billions for defense: the pervasive nature of defensive medicine. Arch Intern Med 1999; 159: 2399-402.

23 Passmore K, Leung W-C. Defensive practice among psychiatrists: a questionnaire survey. Postgrad Med J 2002; 78: 671-3.

24 Alam R, Cheraghi-Sohi S, Panagioti M, Esmail A, Campbell S, Panagopoulou E. Managing diagnostic uncertainty in primary care: a systematic critical review. BMC Fam Pract 2017; 18: 79

25 APA Work Group on Psychiatric Evaluation. The American Psychiatric Association Practice Guidelines for the Psychiatric Evaluation of Adults (3rd edn). American Psychiatric Association, 2016.

26 National Institute for Health and Care Excellence. Structural Neuroimaging in First-Episode Psychosis (Technology Appraisal Guidance TA136). NICE, 2008.

\title{
CULTURAL REFLECTIONS
}

\section{Evensong: how the medical humanities can strengthen a patient-centred approach to both physical and mental health conditions}

\section{Corinne Rowena Dignan 10}

BJPsych Bulletin (2022) 46, 156-158, doi:10.1192/bjb.2021.3

St Cadoc's Hospital, Newport, UK Correspondence to Dr Corinne Dignan (corinne.dignan@wales.nhs.uk)

First received 16 May 2020, accepted 24 Nov 2020

(c) The Author 2021. Published by Cambridge University Press on behalf of the Royal College of Psychiatrists. This is an Open Access article, distributed under the terms of the Creative Commons Attribution licence (http:// creativecommons.org/licenses/by/4. $0 /$ ), which permits unrestricted re-use distribution, and reproduction in any medium, provided the original work is properly cited.
Summary The medical humanities may offer an antidote to the unconscious depersonalisation of patients into clinical variables and diagnoses at the hands of physicians, cultivating a patient-centred and individual approach to the management of both physical and mental health conditions. The emphasis on the person behind the diagnosis helps physicians to remain motivated and compassionate in the face of increasing social and organisational pressures that threaten this human connection. As a doctor and the relative of a patient with dementia, I reflect on the way in which poetry has helped to translate my experience as a relative into improving my own practice as a doctor. This article includes one of the poems I wrote during my grandmother's illness to aid reflection on the patient perspective I gained during her time in hospital, and also a brief commentary exploring the influence this process has had on the interactions I now have with my patients.

Keywords Education and training; dementia; comorbidity; organic syndromes; stigma and discrimination. 
We all have our stories. Our triumphs and our failures, the people we love, the landscapes we create and the goals we pursue; all those days, from the greatest moment to the most mundane, come together to form the fabric of a life.

\section{Presenting complaint}

One of the great privileges of a physician is that our patients share their stories with us, and our eyes witness the momentous: the first cry of new life, the last sigh as old age departs it, and countless tears, smiles and occasional bursts of anger that our involvement in these stories inevitably brings. During my time as a doctor, however, I have noticed that by assigning the role of patient to these individuals within our own narrative, we often, however unconsciously, deprive them of their individual story. They become lists of vital signs, blood results and diagnostic difficulties, the faces of medical conditions that leap out of textbooks into the hospital beds in front of us, embodying the frailty and mortality that is truly such a small part of who they really are.

\section{Past medical history}

I first became sensitised to this when my grandmother's memory faded with vascular dementia, which followed the stroke she suffered while I was at medical school. Her story was lost to the doctors caring for her on the ward, and the impression that they formed of the truculent and demented old woman who obstinately refused her medication was infinitely removed from the independent, active and astute lady of just a few weeks earlier, the one with a roguish twinkle in her eye who loved to sing, laughed often and always cheated at playing cards. This was compounded by the resistance that we, as her relatives, experienced when attempting to engage with the doctors in our new role as proponents of her story, finding that our attempts at advocacy were rejected as an irrelevant distraction from her medical care.

The condensation of a rich and complex individual into the black and white of a clinical diagnosis does our patients a disservice, but it is a phenomenon that many doctors report in their professional practice. For my grandmother it contributed to delays in her diagnosis, a lack of appropriate stroke rehabilitation, a void of professional support and an inexorable decline into depression, incontinence and pressure ulcers. The strain of increasing service demands without a correlating increase in resources and support stands as an obvious culprit, but the influence of compassion fatigue and the unconscious desire to protect our own sanity and emotions when treatments fail and operations do not go to plan cannot be ignored.

\section{Investigations and management}

Reflecting as both a physician and a relative, I realised that I too frequently overlooked the person behind the confused and wandering patients on my ward; I was also too ready to make assumptions about the quality of life of octogenarians, and I recognised the previously unacknowledged dread of the demands of relatives during visiting time while my pager chimed and my list of daily tasks multiplied before my eyes.
To lend some perspective, I started to organise my thoughts and reflections on paper, and soon found that verse provided a structure and rhythm that helped me to understand how I could progress in my own practice and, in my own small way, help families in similar circumstances to my own. The process of writing helped me realise the unique opportunity we have as physicians to gain such an insight into another person's life, and the responsibility of ensuring that we allow patients and their loved ones to tell us a little about the most important things in their lives. Once we understand where a patient has come from, we are in a better position to help them navigate the difficulties they encounter whilst in our care and to ensure that their story can continue in a way that is most congruent with their values. Support from other members of the multidisciplinary team is crucial in providing this holistic care, and the engagement of therapists in rehabilitation, psychologists in support or the chaplain in blessing should not be underestimated.

I wrote this particular poem to give voice to a part of my grandmother's story, highlighting the beautiful things that I remember about her and that I hoped would provide an insight into the person she was and the things that she loved before her illness. To me the process of writing this poem served as a reminder to give all my patients the chance to tell their story, to see past the observation charts and appreciate what truly makes up their lives. Only then can we hope to treat our patients with the compassion and understanding that we hope our own loved ones will experience at the hands of medical professionals; by ensuring that this process starts first with us.

\section{Evensong}

I remember the ardent goldfinches:

a charm in your camellias,

cheeks sanguine as the Eucharist.

A joyful celestial choir

exuding praise and glory

for long sweet days of Litha.

All Gods and old Gods exalted in unison.

I remember the last slivers of sun

lighting shrinking vestiges

of the rapeseed harvest.

We waded together

along faded paths which led

to the field where horses

rose as monoliths in the fading gloom.

I remember the smell of hot sweet apples, the spoon crushing vaulted pastry roof, sinking to the bubbling nave.

Skin still scored and prickling

from circlets of thorns,

the jealous brambles

constraining their inky treasures.

You laughed at their bite and spleen.

I remember the hoary birch branches, prising the silvery vellum

from the resisting trunk

Dancing and unravelling

widdershins around the bole;

sinuous snakes entwining our ankles,

threatening to topple, threatening to fall.

I remember because now you cannot.

A ghost mind astray, 
reneging on its past.

Though your smile tells me

that something flickers

far back in your mind:

a fading spark, in the darkness.

\section{Funding}

This research received no specific grant from any funding agency, commercial or not-for-profit sectors.

\section{Declaration of interest \\ None. \\ An ICMJE form is in the supplementary material, available online at https://doi.org/10.1192/bjb.2021.3.}

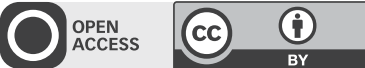

\title{
COMMENTARY
}

\section{Extracurricular pursuits $\uparrow$}

\author{
Jonathan Williams
}

BJPsych Bulletin (2022) 46, 158-160, doi:10.1192/bjb.2021.111

Consultant Child and Adolescent

Psychiatrist, NHS North Central London, UK

Correspondence to Jonathan Williams (johwilliams@gmail.com)

First received 15 Sep 2021, accepted

5 Oct 2021

(c) The Author(s), 2021. Published by

Cambridge University Press on behalf of

the Royal College of Psychiatrists. This is

an Open Access article, distributed

under the terms of the Creative

Commons Attribution licence (https://

creativecommons.org/licenses/by/4.0/)

which permits unrestricted re-use,

distribution, and reproduction in any

medium, provided the original work is

properly cited.
Summary Dr Dignan's poetry, her care, and her enthusiasm should be lauded. There are also many other non-medical pursuits that may make us better doctors. But it is difficult to know which of these are effective or practicable.

Keywords Psychodynamic; psychotherapy; dementia; CPD; extracurricular.
In medical school we used to debate whether we would prefer to be a kind doctor or a clever one. Of course, most of us wanted to be both. But when we were ill ourselves, if we had to choose we were sure we would want a clever doctor to deal with serious conditions and a kind one for the minor things.

There is a related rift in mental health services between psychodynamic work and evidence-based medicine. Certainly, most patients are given one or the other. Corinne Dignan in her article ${ }^{1}$ focuses on something more on the psychodynamic side, that we are in danger of forgetting: the feelings and the shared experiences that she neatly calls the person behind the diagnostic labels. In this commentary I focus on this specific suggestion, rather than the general topic of medical humanities.

$\dagger$ Commentary on... Evensong. See this issue.
To clarify, she is not pushing us to become psychotherapists. She sees a beauty in each person, the special moments in each life and the treasured memories that gradually disappear in dementia. She experiences shared memories as special objects that will die unless a person keeps them alive. Indeed, as long as one person keeps them alive, part of the departed person still exists. In some senses they do; the memories exist, and we may sometimes feel that the person does too. This is a point that I've not seen so well treated elsewhere. Each experience, or at least an echo of it, continues to exist for as long as someone thinks about it (akin to the tree in the quad ${ }^{2}$ ). Dignan's article serves to warn us not to forget John Eccles's World 2 (subjective knowledge) as opposed to Worlds 1 and 3 that doctors usually focus on (physical objects and objective knowledge). ${ }^{3}$

I'm pleased that Dr Dignan is not pushing us all to be poets (I might rebel). Instead, starting from a traditional 